\title{
Study on Characteristic Temperatures of Cooling Saline Soil
}

\author{
Sai Ying, ${ }^{1,2}$ Fengxi Zhou ${ }^{1 *}$, Tao Wen ${ }^{3,4}$ \\ ${ }^{1}$ School of Civil Engineering, Lanzhou University of Technology, Lanzhou 730000, Gansu, China \\ ${ }^{2}$ School of Civil Engineering and Architecture, Wuyi University, Jiangmen 529000, Guangdong, China \\ ${ }^{3}$ Engineering Research Center for Health Monitoring in Building Life Cycle and Disaster Prevention, \\ Yangtze Normal University, Fuling 408100, Chongqing, China \\ ${ }^{4}$ Gansu Academy of Sciences, Lanzhou, 730000, Gansu, China
}

Received: 16 March 2020

Accepted: 18 August 2020

\begin{abstract}
The characteristic temperatures appearing in freezing process of cooling saline soil include the freezing temperature and the supercooling temperature. A thermodynamically consistent equation for calculating the equilibrium temperature is provided, in which the influences of water activity and pore radius are considered. Since the nucleation in soil can be regarded as the heterogeneous nucleation on a plane surface, an equation for calculation of the supercooling temperature is proposed based on the classical nucleation theory. Through comparing the calculated data with the tested data, the equations are proved effective to predict the characteristic temperatures of saline soil. The effects of solution concentration and the pore size on the characteristic temperatures are discussed. In addition, the influence of the contact angel on the supercooling temperature is investigated. The study would be helpful to understand the freezing mechanism of saline soil and useful for hazard prevention of frost heave.
\end{abstract}

Keywords: equilibrium temperature, supercooling temperature, saline soil, freezing mechanism

\section{Introduction}

Sulfate saline soil is widely distributed in the western cold regions of China, the volume of which is sensitive to the change of temperature. Frost heave, salt expansion and thaw collapse of saline soil caused by the changes of temperature lead to great harm to engineering construction in those saline frozen regions [1-3].

*e-mail: geolut@163.com
Due to the fact that latent heat will be released during phase change of water and salt in saline soil, the supercooling temperature and the freezing temperature can be obtained by monitoring the change of temperature of cooling saline soil. The supercooling temperature and the freezing temperature are called characteristic temperature here.

Because the characteristic temperatures are the macroscopic embodiment of freezing process in saline soil in the dimension of heat change, it is a heated topic of the freezing mechanism research of saline soil [4-5]. The characteristic temperatures are also the important parameters in engineering, for they can be used to 
determine soil state, frozen or thawed, to predict the frost depth and the content of unfrozen water [6-7], in the meanwhile, they have a great effect on the water migration [8-9] and the formation of segregating ice and the frost heave in frozen soil [10-12].

The freezing of saline soil is the process of nucleation and growth of ice crystal in pore solution. Although the theory analyses of equilibrium temperature in the view of ice crystal growth were provided in previous literature [13-15], there are few theory analyses and computing methods of the supercooling temperature of saline soil.

In this paper, effective models for calculating the supercooling temperature and the freezing temperature are proposed based on the thermodynamics and the classical nucleation theory. And the influencing factors of characteristic temperatures are extensively analyzed by the calculating model and experiment. This study is helpful to understand the freezing mechanism of saline soil and useful for hazard prevention of frost heave.

\section{Materials and Methods}

\section{Materials and Experimental Methods}

\section{Materials and Sample Preparation}

The loess was collected from an excavation site $\left(36^{\circ} 33.169^{\prime} \mathrm{N}, 103^{\circ} 46.98^{\prime} \mathrm{E}\right)$ at depths from $0.2 \mathrm{~m}$ to $0.6 \mathrm{~m}$ in Lanzhou city, China. To precisely control the salt content of the soil samples, the collected loess was desalting six times with the distilled water. The desalinated soil was dried at $105^{\circ} \mathrm{C}$ for $8 \mathrm{~h}$ and then pulverized with a rubber hammer. The powdered loess was passed through the sieve with a $0.5 \mathrm{~mm}$ aperture. Subsequently, the physical properties of the loess were listed in Table 1. To obtain the soil samples under different salt contents, the loess was mixed uniformly with a series of ordered salt solutions which were prepared with sodium sulfate and distilled water, and the salt contents of samples can be obtained in Fig. 5. The samples for salt-frost heave test were $8 \mathrm{~cm}$ in diameter and $2 \mathrm{~cm}$ in height, and the samples for the characteristic temperatures test were $3.5 \mathrm{~cm}$ in diameter and $3.5 \mathrm{~cm}$ in height. The pore size distribution is presented in Fig. 1, which was measured by mercury porosimetry.

\section{Experimental Apparatus and Testing Procedures}

The cooling bath with temperature accuracy of $\pm 0.05^{\circ} \mathrm{C}$ is used for temperature control. Thermistors

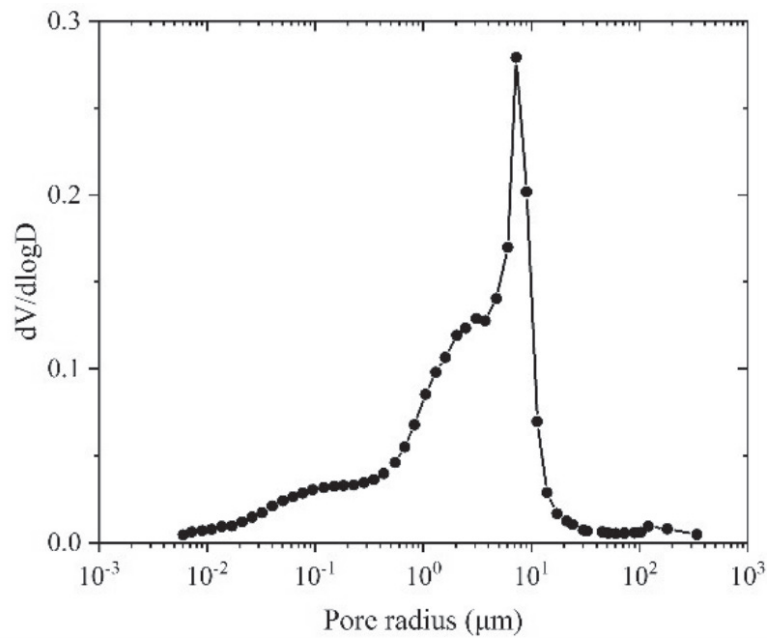

Fig. 1. Pore size distribution curve of sample.

with accuracy of $\pm 0.05^{\circ} \mathrm{C}$ are used for temperature measuring. Thermistors were inserted into samples encased by water proof plastic sheets and then the samples were put into cooling bath. The temperature of the cooling bath changed from $18^{\circ} \mathrm{C}$ to $-15^{\circ} \mathrm{C}$ and the cooling rates in the cooling process equaled $0.3 \pm 0.05^{\circ} \mathrm{C} / \mathrm{min}$. During the cooling process, temperature data were collected every $5 \mathrm{~s}$ by DT 80 .

\section{Theoretical Methods}

\section{Equilibrium Temperature of Solution}

In ice-water system chemical potentials of ice and liquid achieve equilibrium at the temperature called equilibrium temperature $T_{\mathrm{e}}$ [16-17]. In ice-water system, equilibrium temperature $T_{\mathrm{e}}$ is the temperature at the time when chemical potentials of ice and liquid achieve equilibrium. When solution temperature $T$ is below equilibrium temperature $T_{\mathrm{e}}$, the degree of supercooling $\Delta T=T_{\mathrm{e}}-T$ is more than 0 , and driving force for phase transformation is less than 0 , ice crystals start to grow in the solution. When solution temperature $T$ is above equilibrium temperature $T_{\mathrm{e}}$, the degree of supercooling $\Delta T=T_{\mathrm{e}}-T$ is less than 0 , and driving force for phase transformation is more than 0 , ice crystals start to melt in the solution.

The driving force for phase transformation is given by

$$
\Delta g=-\frac{L_{w i}}{N} \frac{\Delta T}{T_{\mathrm{e}}}
$$

Table 1. Physical properties of soil.

\begin{tabular}{|c|c|c|c|c|}
\hline Relative density $\left(\mathrm{g} / \mathrm{cm}^{3}\right)$ & Liquid limit $W_{L} / \%$ & Plastic limit $W_{p} / \%$ & Plasticity index $\mathrm{I}_{\mathrm{p}}$ & $\begin{array}{c}\text { Coefficient of uniformity } \\
C_{u}=d_{60} / d_{10}\end{array}$ \\
\hline 2.69 & 26.8 & 17.6 & 9 & 6.87 \\
\hline
\end{tabular}


...where $N$ is Avogadro constant and $L_{w i}=6010 \mathrm{~J} \mathrm{~mol}^{-1}$ is latent heat of water freezing [18].

For pure water, the equilibrium temperature $T_{0}$ is $0^{\circ} \mathrm{C}$ in normal state. When soluble salt is dissolved in water, it followed that equilibrium temperature in solution changed as a result of the increase of concentration of solution.

In ice-water system when liquid and ice reach the state of equilibrium, the following equation exists:

$$
\mu_{i}(T, p)=\mu_{l}\left(T, p, a_{w}\right)
$$

...Where $\mu_{i}$ is the chemical potential of ice, $\mu_{l}$ is the chemical potential of liquid and $a_{w}$ is activity of water in solution, which can be obtained by the Pitzer model [19].

The chemical potential of salt solution is given by

$$
\mu_{l}=\mu_{l}^{0}+R T \ln a_{w}
$$

...where $\mu^{0}$ is the chemical potential of pure water in normal state, $R$ is the universal gas constant.

Substituting Eq.(3) into Eq.(2) yields an expression for the difference of chemical potential between pure water and salt solution in ice-water system

$$
\mu_{l}-\mu_{l}^{0}=\mu_{i}-\mu_{l}^{0}=R T \ln a_{w}
$$

According to Gibbs-Helmholtz equation at constant pressure, we obtain

$$
\Delta G=\Delta H-T \Delta S
$$

...where $\Delta G, \Delta H$ and $\Delta S$ refer to increment of Gibbs free energy, enthalpy and entropy, respectively, which are caused by phase transformation between water and ice.

If the change of temperature is small, the influence of temperature on enthalpy change can be neglected, in this case $\Delta H \approx L_{w i}$.

The derivatives of $\Delta G$ and $\Delta G / T$ with respect to $T$ take the form

$$
\frac{\partial(\Delta G)}{\partial T}=-\Delta S, \frac{\partial(\Delta G / T)}{\partial T}=-\frac{L_{w i}}{T^{2}}
$$

Substituting Eq.(6) into the derivative of Eq.(4) with respect to $a_{w}$, we can obtain

$$
\frac{1}{a_{w}}=\frac{L_{w i}}{R T^{2}} \frac{\partial T}{\partial a_{w}}
$$

Since $a_{w}$ equals 1 at the temperature of $T_{0}$, the integration of Eq. (7) can be written as

$$
\int_{1}^{a_{w}} \frac{1}{a_{w}} \mathrm{~d} a_{w=} \int_{T_{0}}^{T_{\mathrm{e}}^{\mathrm{s}}} \frac{L_{w i}}{R T^{2}} \mathrm{~d} T
$$

If the interfacial energy between ice and solution is neglected, the equilibrium temperature $T_{\mathrm{e}}^{\mathrm{s}}$ of the solution with the activity of $a_{w}$ can be obtained

$$
T_{\mathrm{e}}^{\mathrm{s}}=\frac{T_{0}}{1-\frac{T_{0} R}{L_{w i}} \ln a_{w}}
$$

The Eq.(9) indicates that the activity of solution has a great influence on the equilibrium temperature $T_{\mathrm{e}}^{\mathrm{s}}$. For the activity of water in solution is related to the concentration of solution, the term of $\ln a_{w}$ in Eq.(9) embodies the effect of concentration of solution on equilibrium temperature $T_{\mathrm{e}}^{\mathrm{s}}$.

For a crystal consisting of $v_{M}$ positive ions $\mathrm{M}$ of charge $z_{M}, v_{X}$ negative ions $\mathrm{X}$ of charge $z_{X}$ and $v_{0}$ molecules of water, the dissolution reaction is given as :

$$
\mathrm{M}_{v_{M}} \mathrm{X}_{v_{x}} \cdot v_{0} \mathrm{H}_{2} \mathrm{O} \rightleftharpoons v_{\mathrm{M}} \mathrm{M}^{z_{\mathrm{M}+}}+v_{\mathrm{X}} \mathrm{X}^{z_{\mathrm{X}-}}+v_{0} \mathrm{H}_{2} \mathrm{O}
$$

According the ion interaction approach, the water activity $a_{w}$ can be calculated by

$$
\ln a_{w}=-\phi \frac{M_{\mathrm{w}}}{1000} v C
$$

...where $v=v_{M}+v_{X}$ is the total number of ions and $C$ is the molar mass concentration of salt in solution. $M_{\mathrm{w}}=18.0153 \mathrm{~g} \mathrm{~mol}^{-1}$ is the molar mass of water. The osmotic coefficient for a single electrolyte is given by

$$
(\phi-1)=\left|Z_{\mathrm{M}} Z_{\mathrm{X}}\right| f^{\phi}+2 C \frac{v_{\mathrm{M}} \nu_{\mathrm{X}}}{v} B_{\mathrm{MX}}^{\phi}+2 C^{2} \frac{\left(v_{\mathrm{M}} v_{\mathrm{X}}\right)^{\frac{3}{2}}}{v} C_{\mathrm{MX}}^{\phi}
$$

...where $f^{\phi}$ is the Debye-Hückle term for the osmotic coefficient, $B^{\phi}{ }_{\mathrm{MX}}$ and $C^{\phi}{ }_{\mathrm{MX}}$ are the second and third virial coefficients in the ion interaction approach. $f^{\phi}$ and $B^{\phi}{ }_{\text {MX }}$ depending on the ionic strength of solution $I$ (mol $\mathrm{kg}^{-1}$ ) can be calculated by following equations:

$$
\begin{gathered}
f^{\phi}=-A_{\phi} \frac{I^{1 / 2}}{1+b I^{1 / 2}} \\
B_{\mathrm{MX}}^{\phi}=\beta_{\mathrm{Mx}}^{(0)}+\beta_{\mathrm{MX}}^{(1)} \exp \left(-\alpha_{1} I^{1 / 2}\right)+\beta_{\mathrm{Mx}}^{(2)} \exp \left(-\alpha_{2} I^{1 / 2}\right) \\
I=\frac{1}{2} \sum_{i} C_{i} z_{i}^{2}
\end{gathered}
$$

...where $z_{i}$ is the charge number of electrolyte ions $i, b=1.2 \mathrm{~kg}^{0.5} \mathrm{~mol}^{-0.5}, a_{1}=1.2 \mathrm{~kg}^{0.5} \mathrm{~mol}^{-0.5}$ and $a_{2}=1.2 \mathrm{~kg}^{0.5}$ mol$^{-0.5}$ are empirical parameters for $\mathrm{Na}_{2} \mathrm{SO}_{4}$ solution. The interaction parameters $B_{\mathrm{MX}}^{(0)}, B_{\mathrm{MX}}^{(1)},{ }_{\mathrm{MX}}^{(2)}$ 
and $C^{\phi}{ }_{\text {MX }}$ are given in Table 2. $A_{\phi}$ is the Debye-Hückle parameter for the osmotic coefficient, which depends on on temperature $T$ [13]:

$$
A_{\phi}=0.13422\left(0.0368329 T-14.627 \ln T-\frac{1530.1474}{T}+80.40631\right)
$$

\section{Equilibrium Temperature of In-Pores Solution}

The water in porous media exists in 3 types: free water, bound water and chemically combined water. It has been well established that the difference of chemical structure and interactions between liquid and the pore walls are extremely important in determining the freezing behaviors of water in pores [20-22]. Due to capillarity action and absorption action in pores, the property of solution confined in pores is different from bulk solution. As a result, the equilibrium temperature of water confined in narrow pores is lower than the equilibrium temperature of free water. The relationship between equilibrium temperature of water in pores $T_{\mathrm{e}}^{\mathrm{p}}$ and pore radius $r$ can be described by Gibbs-Thomson equation:

$$
T_{\mathrm{e}}^{\mathrm{p}}-T_{\mathrm{e}}^{\mathrm{s}}=-\frac{2 v \gamma_{s l} T_{\mathrm{e}}^{\mathrm{s}}}{L_{w} r}
$$

Substituting Eq. (9) into Eq. (17) yields the formula of the equilibrium temperature in pores $T_{\mathrm{e}}^{\mathrm{p}}$ under the influence of pore radius $r$

$$
T_{\mathrm{e}}^{\mathrm{p}}=\frac{T_{0}}{1-\frac{T_{0} R}{L_{w i}} \ln a_{w}}-\frac{2 v \gamma_{s l} T_{\mathrm{e}}^{\mathrm{s}}}{L_{w} r}
$$

\section{Critical Radius of a Nucleus and Nucleation Free Energy Barrier}

The fluctuation of energy in solution causes the interaction of water molecules in solution to form short-lived ice clusters, which are called embryos. The embryos may gain more molecules to grow or they may lose molecules to dissolve, because the embryos are extremely unstable. If an embryo grows beyond a certain critical radius, it becomes a stably growing nucleus.

Since the formation of nuclei induces a depression of system energy in solution, the free energy per unit volume of embryo is lower than that of liquid. At the

Table 2. Parameters of electrolyte solution.

\begin{tabular}{|c|c|c|c|c|}
\hline Salt & $B_{M X}^{(0)}$ & $B_{M X}^{(1)}$ & $B_{M X}^{(2)}$ & $C_{M X}^{\phi}$ \\
\hline $\mathrm{Na}_{2} \mathrm{SO}_{4}$ & 0.1939 & 1.4285 & -0.5954 & -0.008222 \\
\hline
\end{tabular}

same time, the formation of embryo creates new phase boundaries in system, which increases the surface free energy of system. As a result, in the process of embryo formation, the overall change of free energy in system is the sum of the surface excess free energy $\Delta G_{\mathrm{s}}$ and volume excess free energy $\Delta G_{\mathrm{v}}[23]$.

If the volume of a water molecule in ice embryo is $\Omega \mathrm{s}$, the surface energy between ice embryo and liquid is $\gamma$ and ice embryo is a spherical with radius of $r$, the overall excess free energy $\Delta G(r)$ in system is given by

$$
\Delta G(r)=\Delta G_{\mathrm{v}}+\Delta G_{\mathrm{s}}=\frac{4 \pi r^{3} / 3}{\Omega_{\mathrm{s}}} \mathrm{V} g+4 \pi r^{2} \gamma
$$

The relationship between the overall excess free energy $\Delta G(r)$ and nucleus radius $r$ is shown in Fig. 2 .

In the condition of $\Delta g<0, \Delta G_{\mathrm{v}}$ is a negative quantity proportional to $r^{3}$ and the value of $\Delta G_{\mathrm{s}}$ is positive and proportional to $r^{2}$. Therefore $\Delta G(r)$ increases first and then decreases with the increase of $r$. Furthermore, because the maximum value of $\Delta G(r)$ corresponds to the critical nucleus, the radius of critical nucleus and the maximum value of $\Delta G(r)$ can be obtained by maximizing Eq. (12), setting $\mathrm{d} \Delta G(r) / \mathrm{d} r=0$ :

$$
r^{*}=-\frac{2 \gamma \Omega_{\mathrm{s}}}{\Delta g}
$$

$$
\Delta G\left(r^{*}\right)_{\text {hom }}=\frac{16}{3} \frac{\pi \Omega_{s}^{2} \gamma^{3}}{\Delta g^{2}}
$$

The behavior of a newly created ice embryo depends on its size. It can either grow or redissolve, but the process which it undergoes is bond to result in the decrease in the free energy of the system. Therefore, critical radius $r^{*}$ represents the minimum size of the

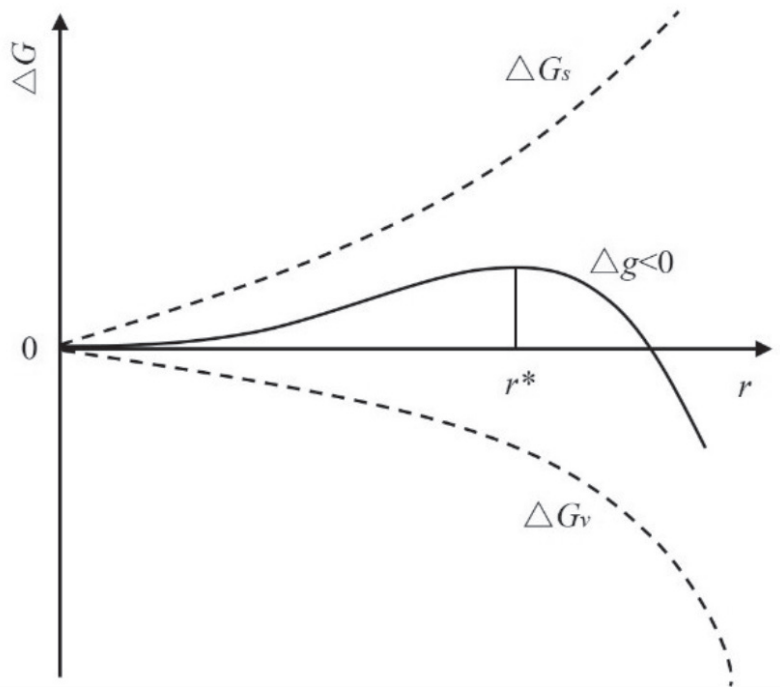

Fig. 2. Free energy diagram for nucleation. 
ice nucleus. Ice embryo smaller than $r^{*}$ will dissolve, because only in this way can the system achieve a reduction in its free energy. Similarly, ice embryo larger than $r^{*}$ will continue to grow.

In a solution system without ice crystal, ice nuclei is generated before the formation of ice crystal. Since a barrier energy $\Delta G\left(r^{*}\right)_{\text {hom }}$ must be overcome to create a nucleus, it means nucleation requires a certain degree of supercooling to overcome the barrier energy. As a result the temperature at nucleation of ice is lower than the equilibrium temperature. In a solution system, impurities acting as the catalyst can reduce the barrier energy of nucleation. The nucleation is called heterogeneous nucleation if catalysts exist in solution, and a homogeneous nucleation without any effect of impurities is not a common event. Because the particles of soil acting as the catalyst is much bigger than ice nuclei, the nucleation in soil can be regarded as the heterogeneous nucleation on a plane surface, of which the barrier energy is given by

$$
\Delta G\left(r^{*}\right)_{\text {het }}=\frac{16}{3} \frac{\pi \Omega_{s}^{2} \gamma^{3}}{\Delta g^{2}} f(m)
$$

...where

$$
f(m)=\frac{2-3 m+m^{3}}{4}
$$

In Eq. (23) $m$ is the cosine of contact angle $\theta$ at the junction of three phases: catalyst $\mathrm{C}$, fluid $\mathrm{F}$ and solid $\mathrm{S}$, which is shown in Fig. 3. The three interfacial tensions are donated by $\gamma_{\mathrm{SC}}$ (between the solid $\mathrm{S}$ and the catalyst C), $\gamma_{\mathrm{CF}}$ (between the catalyst $\mathrm{C}$ and the fluid $\mathrm{F}$ ) and $\gamma_{\mathrm{SF}}$ (between the solid S and the fluid F). Because the mechanical equilibrium is achieved at the junction of three phases, we obtain

$$
\cos \theta=\frac{\gamma_{\mathrm{SC}}-\gamma_{\mathrm{CF}}}{\gamma_{\mathrm{SF}}}
$$

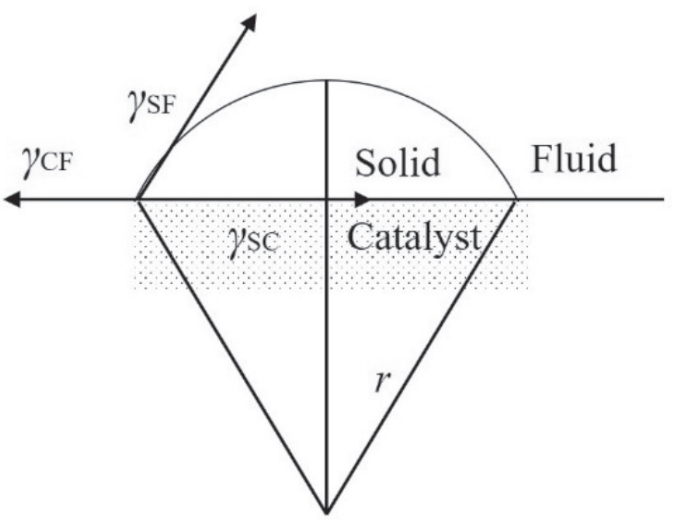

Fig. 3. Interfacial tensions at the boundaries between three phases.
As $0^{\circ} \leq \theta \leq 180^{\circ}$ we can see that $-1 \leq m \leq 1$. Refer to Eq. (24), we can get $0 \leq f(m) \leq 1$. This indicates that catalyst can reduce the barrier energy in nucleation.

\section{Supercooling Temperature of In-Pore Solution}

The rate of nucleation $I$ is the number of new nuclei formed per unit time in unit area, which is given by an expression of the form

$$
I=4 \pi 10^{25} r^{2} \exp \left(-\Delta G\left(r^{*}\right) / k T\right)
$$

...where $k$ is the Boltzmann constant [24].

The critical rate of nucleation is defined as one embryo per $\mathrm{cm}^{3}$ per second which corresponds to the critical degree of supercooling [23]. Since the rate of nucleation $I$ shows an exponential relation with $\Delta G\left(r^{*}\right)$, when the degree of supercooling is lower than the critical degree of supercooling, the rate of nucleation $I$ is almost equal to 0 . But when the degree of supercooling equals the critical degree of supercooling, the ice nuclei will burst out in a discontinuous way. If we make Eq. (25) equal $1 \mathrm{~cm}^{-3} \mathrm{gs}^{-1}$, a formula to calculate the supercooling can be obtained

$$
\Delta T^{*}=\left[\frac{8 \pi T \gamma^{3} \Omega_{s}^{2} f(m)}{3 k\left(\frac{L_{w}}{N}\right)^{2}\left(60.1+4.604 \log _{10} r^{*}\right)}\right]^{\frac{1}{2}}
$$

If given values of $m$ and an arbitrary $r^{*}$, Eq. (26) gives a value of the critical degree of supercooling $\Delta T^{*}$. Substitute this value into Eq.(1) and (20), and a more accurate $r^{*}$ will be found. Once the values of $\Delta T^{*}$ is obtained by this successive approximation approach, the supercooling temperature $T_{s}$ can be calculated in following formula:

$$
T_{s}=T_{e}^{p}-\Delta T^{*}
$$

\section{Results and Discussion}

\section{Test Result}

The change of temperature of saline soil derives from the heat exchange with the environment. Once crystallizing, water and salt will release the latent heat, which will cause an abrupt change of temperature. When a large number of ice crystals form in saline soil, we can obtain the characteristic temperatures from the characteristic points in temperature variation curve, as shown in Fig. 4.

The curves of temperature in cooling saline soil samples obtained from the experiment are shown in 


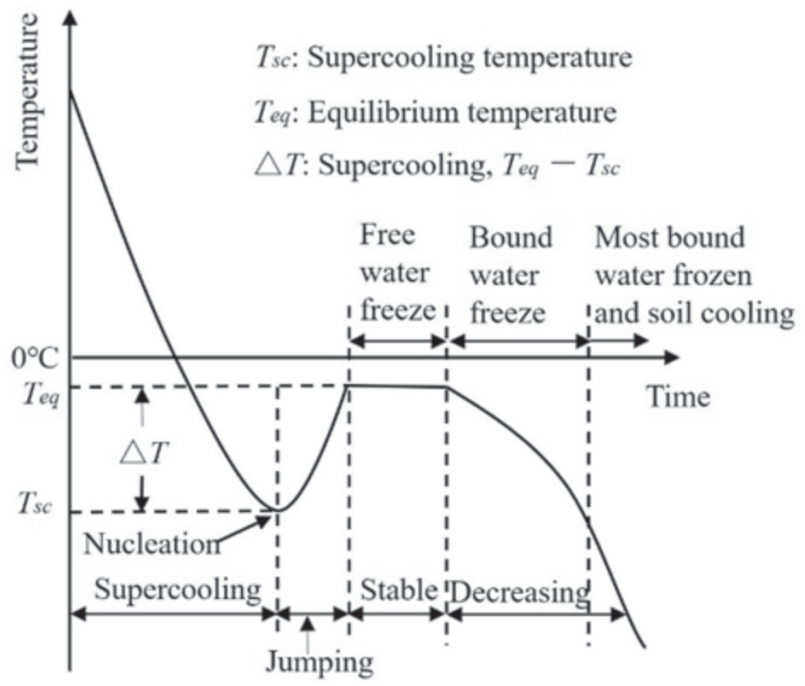

Fig. 4. Typical cooling curve of frozen soil.

Fig. 5. The supercooling temperatures and equilibrium temperatures can be obtained from Fig. 5, and the values and change law of characteristic temperatures will be given in following analyses in detail.

\section{Analysis of Equilibrium Temperature}

The relationship between water activity and concentration of $\mathrm{Na}_{2} \mathrm{SO}_{4}$ solution, shown in Fig. 6, was calculated by Eq. (8). The relationship curve in Fig. 6 shows that the water activity decreases with increasing concentration of $\mathrm{Na}_{2} \mathrm{SO}_{4}$ solution, and we can learn from Eq. (6) that the decrease of water activity will lead to a depression of equilibrium temperature of $\mathrm{Na}_{2} \mathrm{SO}_{4}$ solution. The relationship between the equilibrium temperature and the concentration of $\mathrm{Na}_{2} \mathrm{SO}_{4}$ solution was calculated by Eq. (6) and is shown in Fig. 7. The comparison of calculated values and tested values of the

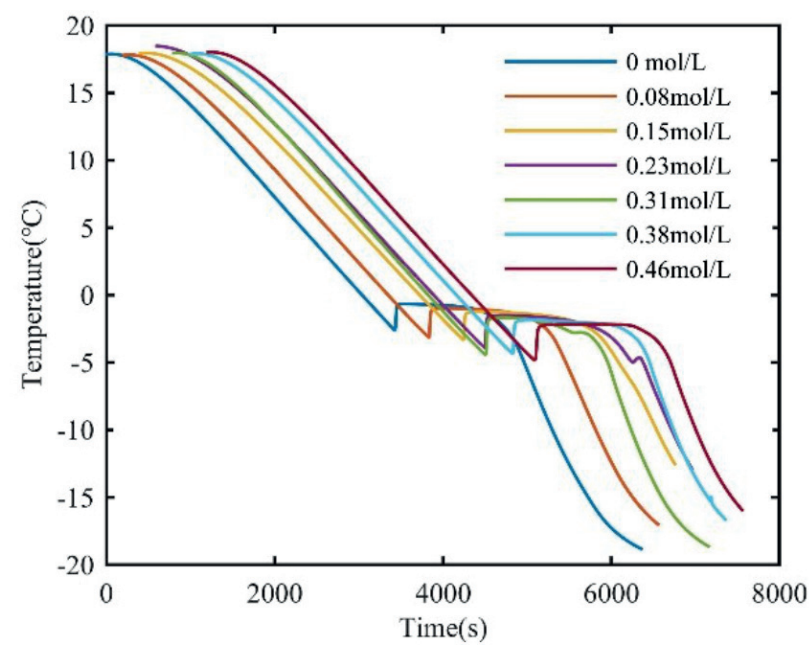

Fig. 5. The cooling curves of samples with different salt contents.

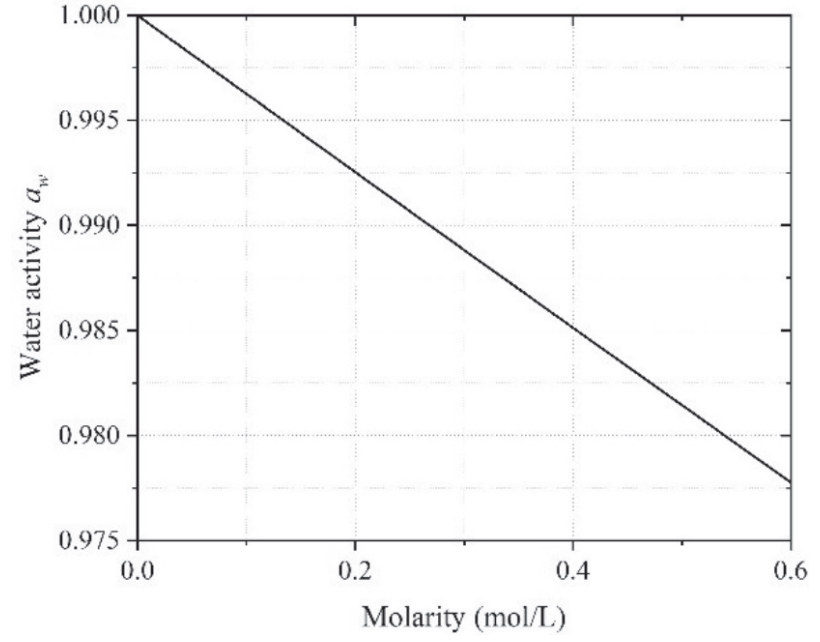

Fig. 6. The relationship between water activities and solution concentration of $\mathrm{Na}_{2} \mathrm{SO}_{4}$ solution at $0^{\circ} \mathrm{C}$.

equilibrium temperature indicates that the calculating model is effective.

For the capillary effect and absorption of pores induce the depression of equilibrium temperature in pores, the relationship between pore size and the equilibrium temperature is calculated by equation (11) and is shown in Fig. 8. From Fig. 8, we can find that due to the capillary effect and absorption of pores, the equilibrium temperature decreases as pore size decreases. Furthermore, the pore radius dependence of equilibrium temperature is remarkable when the pore radius is less than $0.1 \mu \mathrm{m}$. Because the freezing temperature and melting temperature both equal equilibrium temperature, we can conclude that the melting temperature in a big pore is lower than that in a small pore. This conclusion is in remarkable agreement with the experiment results that the melt of ice in small pores come ahead of in big pores in porous media [25].

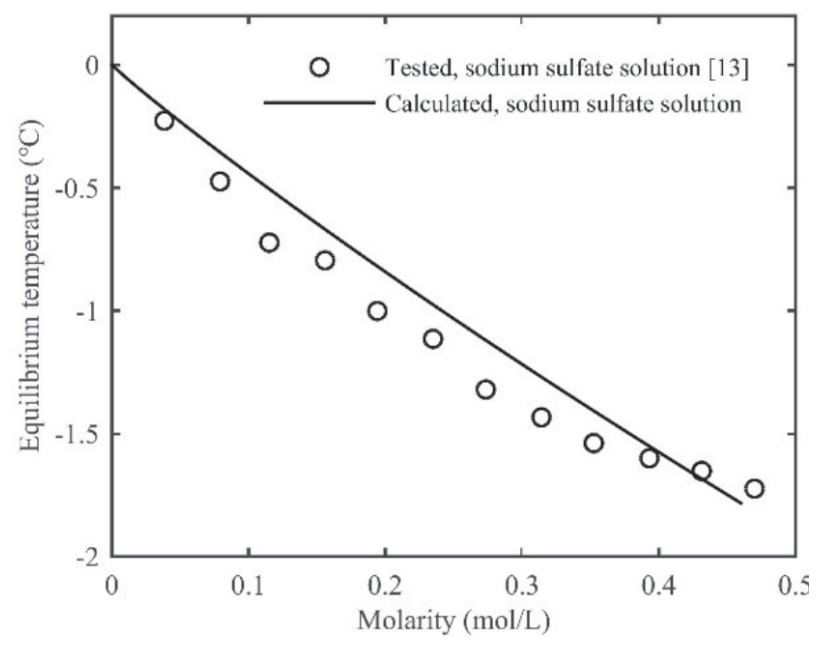

Fig. 7. Equilibrium temperatures of $\mathrm{Na}_{2} \mathrm{SO}_{4}$ solutions with different salt concentrations. 


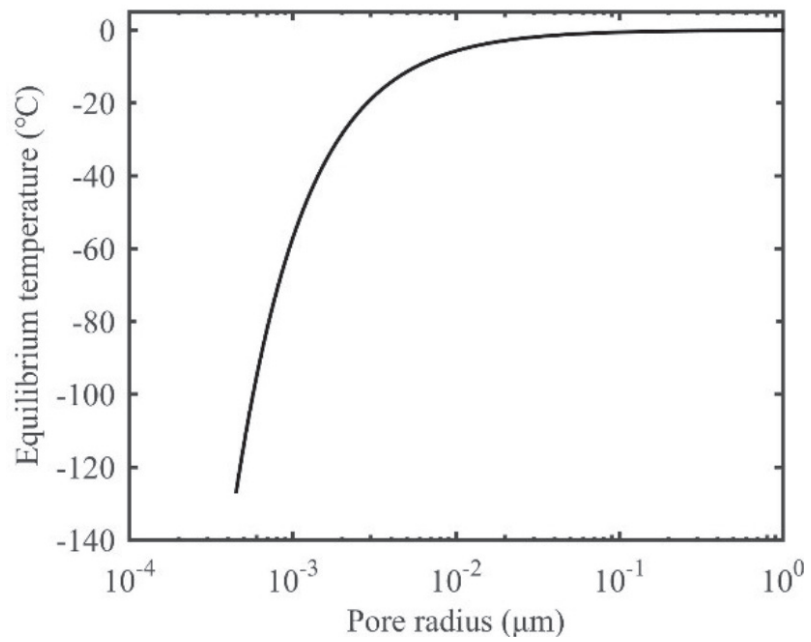

Fig. 8. Equilibrium temperatures of pure water in different pores.

Since the capillary effect and absorption of clay are stronger than that of sand, the equilibrium temperature of clay is lower than that of sand, and some experiments prove this point $[4,25]$.

For soil is a kind of porous media, the different pores in soil contain different equilibrium temperature. As a result, the equilibrium temperature of soil equals the equilibrium temperature of a certain pore in it, which is called the equivalent pore. The radius of equivalent pore is dependent of the pore size distribution and surface properties of soil particles, therefore it is not equal the mean radius. Only by the fitting of experiment data, can we get the value of the radius of the equivalent pore [14, $15]$.

According to the experiment data of equilibrium temperatures of samples with different salt contents, we obtain that the equivalent pore radius of Lanzhou loess is $0.11 \mu \mathrm{m}$, and Qinghai Tibet silty soil is $0.15 \mu \mathrm{m}$. Using Eq. (15), the equilibrium temperatures of

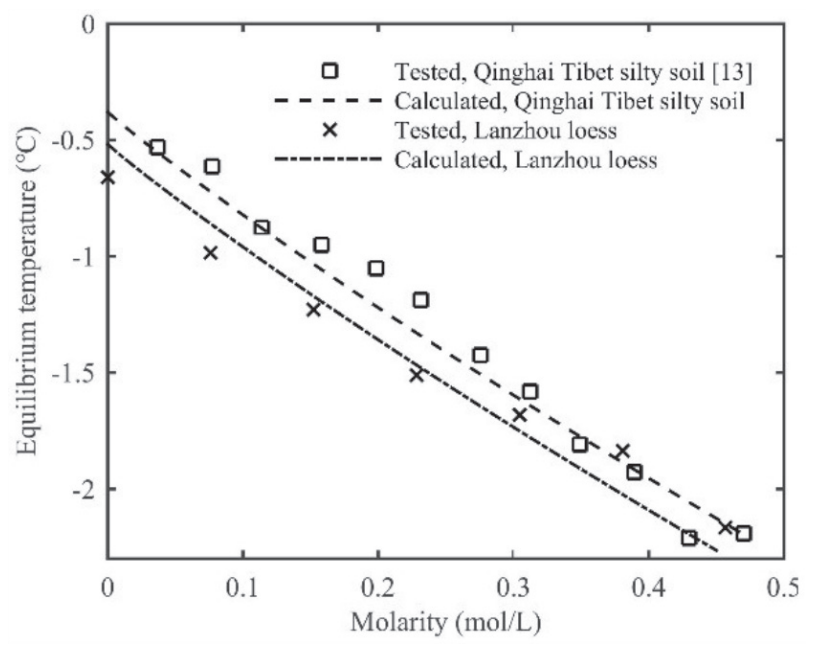

Fig. 9. Equilibrium temperatures of saline soil with different salt concentrations.

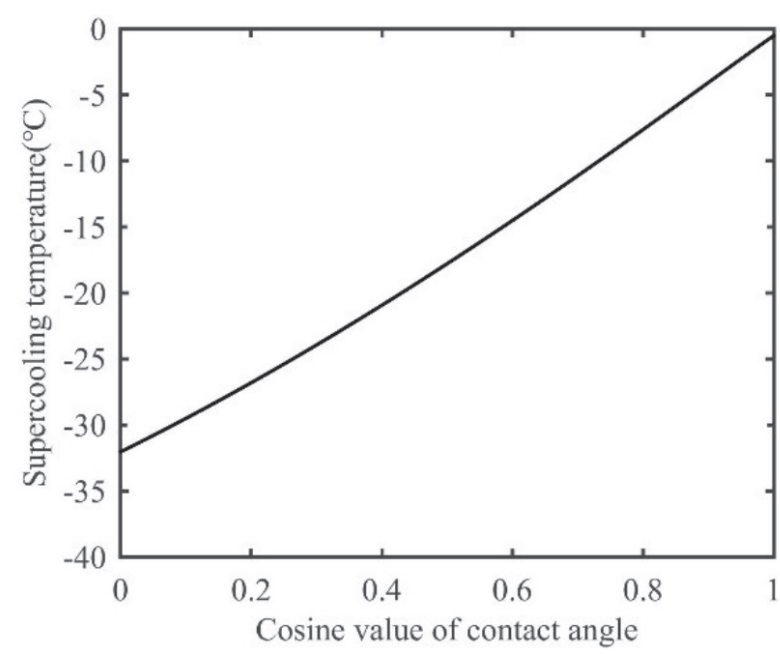

Fig. 10. The relationship between the supercooling temperature and the cosine of contact angle $\theta$.

Lanzhou loess, Qinghai Tibet silty soil were computed and the results are shown in Fig. 9, in which we can see that the calculation results agree well with the test data.

\section{Analysis of Supercooling Temperature}

When temperature goes down to equilibrium temperature, soil will not freeze immediately. Only when temperature is below supercooling temperature do ice crystals come into being in solution. The supercooling temperature of soil can be calculated by Eq. (20) considering the remarkable dependence of supercooling temperature on contact angle. From the curve in Fig. 10 we can see that when $\theta=0^{\circ}$, the surface of catalyst is completely wetted by crystal. In this case the barrier energy of nucleation is vanished and the critical supercooling is minimum. With the increase of contact angle the catalytic action is weakened and the critical supercooling increases. Until the catalytic action

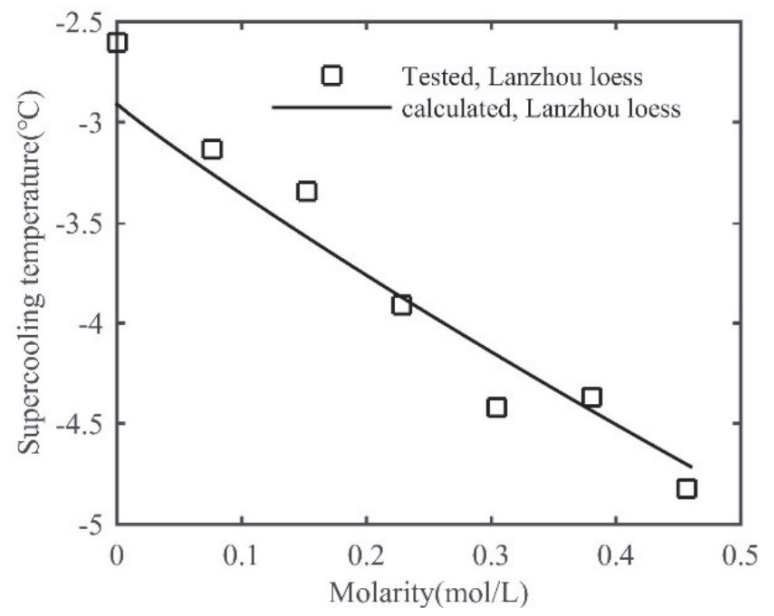

Fig. 11. The relationship between the supercooling temperature and the salt content. 


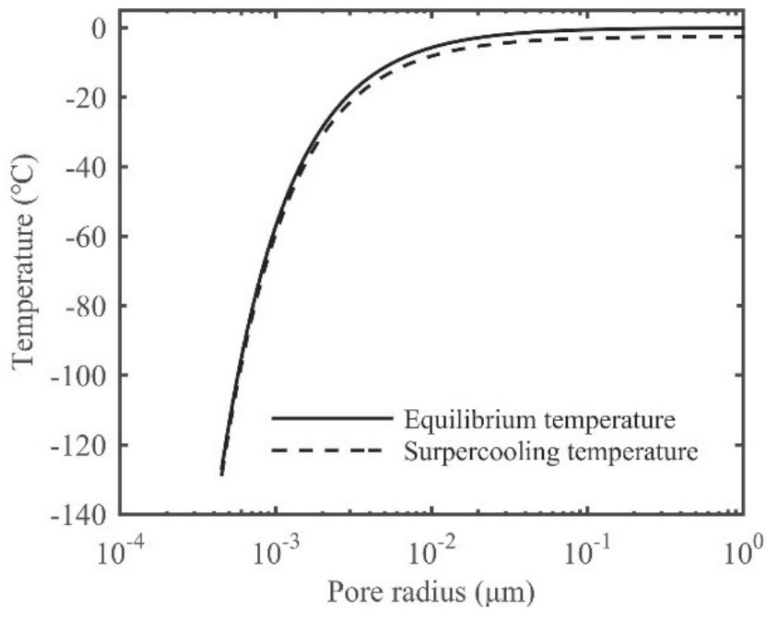

Fig. 12. The characteristic temperatures in different pores.

disappears and the critical supercooling achieves the maximum value of $0^{\circ} \mathrm{C}$ at $\theta=180^{\circ}$, the nucleation of this case is the same with homogeneous nucleation and the supercooling temperature equals the equilibrium temperature.

As a kind of hydrophilic material, the contact angle of soil is small. Therefore as a catalyst, soil particles can effectively reduce the barrier energy and the supercooling of nucleation, making the supercooling temperature of solution in soil higher than that of bulk solution. The contact angle is determined by the physical and chemistry surface properties of soil particle. Although the value of contact angle is hard to measure directly, it can be obtained by data fitting of supercooling temperature.

Using the data of supercooling temperatures and equation (25) to fit the parameter of $m$, we obtain the $m$ of Lanzhou loess which is 0.932. Substituting $m$ into equation (25), we get the values of supercooling temperatures of Lanzhou loess. The calculated values of supercooling temperatures in Fig. 11 coincide well with the tested values. We also can see from Fig. 11 that the supercooling temperature goes down with the increase of solution concentration.

The supercooling temperature is also affected by pore size. As shown in Fig. 12, the decreasing radius reduces the supercooling temperature and supercooling as well. As a result, we can see that in porous media the freezing of solution occurs in big pores first and then occurs in small pores. There will still exist some unfrozen narrow pores when the temperature is very low, and that is one of the reason why there will exist unfrozen water in frozen soil. As mentioned before the higher concentration of the solution is, the harder it is to be frozen. If temperatures are the same and are below the supercooling temperatures, the higher concentration of the solution is, the more unfrozen pores it will be, so does the unfrozen water. This conclusion is in agreement with experiment results $[1,25]$.

\section{Conclusions}

The characteristic temperatures are the macroscopic embodiment of cooling freezing process in saline soil in the dimension of heat change and also are the important engineering parameters for cold region construction. In this paper, models for calculating the characteristic temperatures are provided based on thermodynamics and the classical nucleation theory. The proposed models are proved to be reliable by comparing the calculated data with the tested data. The influencing factors of the characteristic temperatures are extensively analyzed and the following conclusion are obtained:

(1) Considering the influence of the ion interaction in solution, the Pitzer model is used to calculate the effect of water activity on the equilibrium temperature. For the increase of the solution concentration reduce the water activity, according to the calculating model of the equilibrium temperature, the equilibrium temperature decreases with the increasing of the solution concentration.

(2) Due to capillarity action and absorption action in pores, the equilibrium temperature of water confined in narrow pores is lower than the equilibrium temperature of free water and the equilibrium temperature decreases as the pore size decreases.

(3) Because of the existence of the barrier energy in the process of ice nucleation, the supercooling temperature lower than the corresponding equilibrium temperature. The supercooling temperature goes down with the increase of solution concentration and the decreasing radius reduces the supercooling temperature. Besides the impact of solution concentration and the pore size, the supercooling temperature is closely related to the contact angle $\theta$ between the soil and ice. With the increase of contact angle $\theta$ the supercooling temperature increases, and the supercooling temperature equals the equilibrium temperature when the contact angle $\theta=180^{\circ}$

\section{Acknowledgements}

This research is supported in part by the National Natural Science Foundation of China (Grant number: 11962016) and Youth Program of Scientific and Technological Innovation Fund of Gansu Academy of Sciences (Grant number: 2019QN-04) and is a part of the Funds for Creative Research Groups of Gansu Province, China (Grant No. 20JR5RA478).

\section{Conflict of Interest}

The authors declare that there are no conflicts of interest regarding the publication of this paper. 


\section{Referencess}

1. XU X., WANG J., ZHANG L. Frozen soil physics. Beijing Science and Technology Press, Beijing, China. 2010.

2. XU X., WANG J., ZHANG L. Mechanisms of frost heave and soil expansion of soils. Science Press, Beijing, China. 1995.

3. LAI Y., ZHANG M., LI S. Frozen soil physics. Beijing Science and Technology Press, Beijing, China. 2009.

4. ZHOU J., TAN L., WEI C., WEI H. Experimental research on freezing temperature and super-cooling temperature of soil, Rock and Soil Mechanics, 36 (3), 777, 2010.

5. HAN Y., WANG Q., KONG Y., CHENG S., WANG J., ZHANG X., WANG N. Experiments on the initial freezing point of dispersive saline soil. Catena, 171, 681, 2018.

6. ZHANG L., XU X., DENG Y., ZHANG Z. Study of the relationship between the unfrozen water content of frozen soil and pressure. In Proceedings of the Seventh International Conference on Permafrost, 1223, 1998.

7. HUANG S., LIU Q., LIU Y., YE Z., CHENG, A. Freezing strain model for estimating the unfrozen water content of saturated rock under low temperature. International Journal of Geomechanics, 18 (2), 04017137, 2018.

8. WU D., LAI Y., ZHANG M. Heat and mass transfer effects of ice growth mechanisms in a fully saturated soil. International Journal of Heat and Mass Transfer, 86, 699, 2015.

9. GAO G.Y., ZHOU F.X., WANG X. Steady-state analysis of heat-moisture-salt coupling in unsaturated layered soil. Environmental Geotechnics, 1, 2019.

10. LAI Y., WU D., ZHANG M. Crystallization deformation of a saline soil during freezing and thawing processes. Applied Thermal Engineering, 120, 463, 2017.

11. KONRAD J.M. Temperature of ice lens formation in freezing soils. In Proceedings of 5th International Conference on Permafrost. Trondheim, Norway: Tapir Publishers, 384, 1988.

12. STYLE R.W., PEPPIN S.S., COCKS A.C., WETTLAUFER J.S. Ice-lens formation and geometrical supercooling in soils and other colloidal materials. Physical Review E, 84 (4), 041402, 2011.

13. WAN X., LAI Y., WANG C. Experimental study on the freezing temperatures of saline silty soils. Permafrost and Periglacial Processes, 26 (2), 175, 2015.

14. WANG C., LAI Y., YU F., LI S. Estimating the freezingthawing hysteresis of chloride saline soils based on the phase transition theory. Applied Thermal Engineering, 135, 22, 2018.
15. XIAO Z., LAI Y., ZHANG M. Study on the freezing temperature of saline soil. Acta Geotechnica, 13 (1), 195, 2018.

16. DASH J.G., REMPEL A.W., WETTLUFER J.S. The physics of premelted ice and its geophysical consequences. Reviews of modern physics, 78 (3), 695, 2006.

17. KOZLOWSKI T. Soil freezing point as obtained on melting. Cold regions science and technology, 38 (2-3), 93, 2004.

18. ICKES L., WELTI A., HOOSE C., LOHMANN U. Classical nucleation theory of homogeneous freezing of water: thermodynamic and kinetic parameters. Physical Chemistry Chemical Physics, 17 (8), 5514, 2015.

19. PITZER K.S. Activity Coefficients in Electrolyte Solutions: 0. CRC press, 2018.

20. JIANG Q., WARD M.D. Crystallization under nanoscale confinement. Chemical Society Reviews, 43 (7), 2066, 2014.

21. KHVOROSTYANOV V.I., CURRY J.A. Thermodynamic theory of freezing and melting of water and aqueous solutions. The Journal of Physical Chemistry A, 108 (50), 11073, 2004.

22. SLIWINSKA-BARTKOWIAK M., GRAS J., SIKORSKI R., RADHAKRISHNAN R., GELB L., GUBBINS K.E. Phase transitions in pores: Experimental and simulation studies of melting and freezing. Langmuir, 15 (18), 6060, 1999.

23. MULLIN J.W. Crystallization. Elsevier, 2001.

24. FLETCHER N.H. Size effect in heterogeneous nucleation. The Journal of chemical physics, 29 (3), 572, 1958.

25. LU X., SHI H., LI R., LIANG J., XU Z., BU H. NMRbased research on unfrozen water and pore water content in saline freezing-thawing soils. Journal of soil and water conservation, 31 (2), 111, 2017.

26. ATKINS P.W., DE PAULA J., KEELER J. Atkins' physical chemistry. Oxford university press, 2018.

27. MORISHIGE K., KAWANO K. Freezing and melting of water in a single cylindrical pore: The pore-size dependence of freezing and melting behavior. The Journal of chemical physics, 110 (10), 4867, 1999.

28. XIAO Z., LAI Y., YOU Z., ZHANG M. The phase change process and properties of saline soil during cooling. Arabian Journal for Science and Engineering, 42 (9), 3923, 2017. 
